\title{
Electric Drive Vehicle Model and Simulation with MATLAB
}

\section{Burak URAZEL ${ }^{1 *}$, Kemal KESKINN ${ }^{1}$}

\begin{abstract}
In this manuscript an electric drive vehicle (EDV) is modeled in the MATLAB/Simulink environment. First the resistive forces acting on EDV during the longitudinal motion are computed analytically. Then the required engine power to propel the vehicle during motion or the regenerated power to charge the batteries during braking is calculated by using powertrain and engine parameters. Finally battery charge/discharge currents, battery charge/discharge powers and battery state of charge (SOC) values are obtained. The proposed vehicle model is simulated with three different drive cycles such as: UDDS (Urban Dynamometer Driving Schedule), NEDC (The New European Driving Cycle) and NREL (National Renewable Energy Laboratory Class-3). Simulations are conducted considering SOC (state of charge) of battery, power demand and speed profile.
\end{abstract}

Keywords: Drive Cycle, Electric vehicle, MATLAB/Simulink, Modelling

\footnotetext{
${ }^{1}$ Burak URAZEL (Orcid ID: 0000-0002-3221-9854), Kemal KESKİN (Orcid ID: 0000-0002-3969-2396), Eskişehir Osmangazi Üniversitesi, Mühendislik Mimarlık Fakültesi, Elektrik Elektronik Mühendisliği Bölümü, Eskişehir, Türkiye

*Sorumlu Yazar/Corresponding Author: Burak URAZEL, e-mail: burazel@ogu.edu.tr 


\section{INTRODUCTION}

The global warming and the environmental deterioration are two important issues that the world is encountering nowadays. A major factor that causes to this issue is the growing rate of polluting and precarious gas emissions. Transportation is the critical contributor to hazardous gas emissions since most of vehicles are using internal combustion engines which burn fossil fuels. Gas emissions should be kept under control and it is required to take precautions in order to minimize existing emissions. The efficiency of internal combustion engine for higher loads is satisfactory, however, they are mostly operated at lower engine loads and as a result of this the overall efficiency decreases (Heywood, 1988). When gas emissions and efficiency are taken into account, the electric drive vehicles (EDVs) can be solution since they have no tail pipe emissions and they are more efficient (Amjad et al, 2010).

EDV s consist of an electric motor which is powered by built-in battery unlike internal combustion engine and fuel tank. The battery is charged with plug-in charging unit during the vehicle is not in use (Tie SF and Tan CW, 2013; Peng M et al. 2012). There are many benefits to use EDVs, for instance, they have zero emission, and also provide favorable acceleration and efficient motor power. In addition, they enable further usage of renewable energy sources with charging battery. Besides that low cost electricity can be used by charging overnight (Amjad et al., 2010; Shareef et al., 2016; Castro et al., 2017). Although EDVs are seem to be excellent for use in transportation, they have already some weaknesses. The main electric storage system, battery, is still overpriced and the trade-off between the range of vehicle and time cost of charging process is not fulfilling yet. Location of charging units are important and the cost of infrastructure for these units are expensive (Hota et al., 2013).

The most important circumstance that affects design level of an EDV is obtaining efficient fuel economy and being respectful to environment. Besides that the vehicle should satisfy performance requirements such as good acceleration (Amjad et al., 2010). The EDV's performance is ensured by the maximum power of engine and the capacity of the energy storage system. Acceleration, braking range and maximum power of electric motor are the main parameters for choosing appropriate engine. Besides, vehicle features such as weight, type etc. are the main constraints for design (Matsuo and Miyamoto, 2000). Other important component of EDV is energy storage unit or in other words battery. Energy storage should meet not only the power requirements of EDV but also driving range necessity. The battery should store sufficient power and also satisfy peak powers such that electric motor needs instantaneous power throughout the acceleration (Burke, 2007).

Mathematical model of EDV is represented by various researchers in the literature (Larminie and Lowry, 2012; Schaltz, 2011). The electric drive vehicle was modeled through Newton's laws of motion (Ehsani, 2013). Besides that a kinematic model of electric drive vehicle on a planar and horizontal road was modeled considering longitudinal and lateral dynamics (Suh et al., 2013). In addition, multi degree of freedom dynamics of an electric drive vehicle was proposed in (Hegazy et al., 1999). In this manuscript, an analytical model and simulation of EDV will be proposed using MATLAB/Simulink environment. The components of EDV will be explained in details and also they will demonstrated by Simulink blocks. The proposed vehicle model will be simulated with three different drive cycles such as: UDDS (Urban Dynamometer Driving Schedule), NEDC (The New European Driving Cycle) and NREL (National Renewable Energy Laboratory Class-3). Simulation results will be evaluated considering SOC (state of charge) of battery, power demand and speed profile. 


\section{MODELING THE MOTION}

Longitidunal motion of a vehicle can be modeled based on Newton's second law, and demonstrated in the following form:

$$
F_{\text {net }}=m_{\text {eff }} a
$$

where $F_{n e t}$ refers to net force acting on the vehicle while $a$ stands for acceleration of the vehicle. Also $m_{\text {eff }}$ is the effective mass of vehicle which consists of the actual mass and the equivalent mass of the rotational inertia placed at vehicle's center of gravity. The effective mass which is subjected to the engine torque can be formulated as follows:

$$
m_{e f f}=m+m_{e q}
$$

where $m$ is the vehicle's actual mass, $m_{e q}$ is the equivalent mass of the rotational inertia which placed at vehicle's center of gravity. The net force acting on the vehicle in longitudinal direction can be determined by following statement:

$$
F_{n e t}=F_{x}-R_{A}-R_{R} \pm R_{G}
$$

where $F_{x}$ is the traction force when accelerating and braking force when decelerating. The other forces acting on vehicle are aerodynamic drag resistance, $R_{A}$, rolling resistance, $R_{R}$, and gradient resistance, $R_{G}$, respectively.

\section{Resistive Forces}

However resistive forces affect the vehicle motion in a negative manner, sometimes, a few of them contribute the vehicle motion positively. For instance, considering a track with uphill and downhill parts, gradient resistance will be negative in downhill part while it is positive in uphill part. Also inertial resistance changes to negative from positive when vehicle is decelerating. Following subsections determine the resistance forces in detail.

\section{Aerodynamic Drag Resistance}

The aerodynamic drag resistance can be formulated based on relative velocity between the vehicle and the wind. It is given by the following statement:

$$
R_{A}=0.5 A \rho C_{d}\left(v_{\text {vehicle }} \pm v_{\text {wind }}\right)^{2}
$$

where $R_{A}$ is the aerodynamic drag force [N],A is the cross-sectional area of the vehicle $\left[m^{2}\right], \rho$ is the air density $\left[\mathrm{kg} / \mathrm{m}^{3}\right], C_{d}$ is the drag coefficient, $v_{\text {vehicle }}$ and $v_{\text {wind }}$ are forward velocity of the vehicle and the velocity of the wind $[\mathrm{m} / \mathrm{s}$ ], respectively. The direction of wind has critical impact on calculation of aerodynamic drag force. If the wind velocity stands in the opposite direction of the vehicle velocity (against the vehicle motion), then plus-minus sign in the formulation (4) will be plus (+). In the case of wind velocity is in the same direction with the vehicle velocity, plus-minus sign in (4) will be minus (-). 


\section{Rolling Resistance}

A force arises from the tire and the road surface interaction which resists the vehicle motion is called as rolling resistance or rolling friction. It is related to the vertical force on the tire and can be formulated as follows:

$$
R_{R}=f W \cos \theta \text { or } R_{R}=f m g \cos \theta
$$

where $R_{R}$ is the rolling resistance [N],f is the rolling resistance coefficient, $W$ is the weight of vehicle $[N], m$ is the mass of vehicle $[\mathrm{kg}], g$ is the gravitational acceleration, and $\theta$ is the angle of incline. When a motion is considered in the level, the angle of incline will be equal to 0 and the contribution of cosinus term to formulation will be 1 . It is clear that when the incline angle rises, the rolling resistance decreases. The most important factor that affects the rolling resistance is tire deformation. It is roughly the reason of rolling resistance with the rate of $90 \%$.

\section{Gradient Resistance}

Throughout the motion of a vehicle, the road level changes variously. However moving through the uphill segment of the road causes a resistance to the motion, it is obvious that it promotes the motion when the vehicle is moving the downhill segment of the road. Hence the force caused by gradient can be positive or negative according to its type and can be obtained as:

$$
R_{G}= \pm W \sin \theta \quad \text { or } \quad R_{G}= \pm m g \sin \theta
$$

where $R_{G}$ is the gradient resistance.

\section{Traction Force}

The traction force provides force to move the vehicle along the longitudinal direction of road. It is occurred at the tire and road contacting surface with the help of generating rotation of the wheels by the drivetrain and engine. Wheel torque and wheel power are two important topics that should be considered before traction force.

Wheel torque is a function of engine torque. The source of torque is the engine and the torque is transmitted to gearbox by using clutch. Hence the torque of wheel can be formulated as follows:

$$
T_{w}=T_{e} i_{g} i_{f} \eta_{t}
$$

where $T_{w}$ is the wheel torque $[\mathrm{Nm}], T_{e}$ is the engine torque $[\mathrm{Nm}], i_{g}$ is the gearbox reduction ratio, $i_{f}$ is the final drive reduction ratio, $\eta_{t}$ is the transmission efficiency. When equation (7) is written again in terms of the wheel power: 


$$
\begin{aligned}
& T_{w}=1000\left(P_{w} / \omega_{r}\right) \\
& T_{w}=\frac{P_{w} 1000}{2 \pi\left(N_{w} / 60\right)} \\
& T_{w}=\frac{9550 P_{e} \eta_{t}}{N_{w}} \\
& T_{w}=\frac{9550 i_{g} i_{f} \eta_{t} P_{e}}{N_{e}}
\end{aligned}
$$

where $P_{w}$ and $P_{e}$ refer to wheel power and engine power $[k W]$, respectively. $N_{e}$ and $\omega_{r}$ are engine rotational speed $[\mathrm{rpm}]$ and wheel rotational speeds $[\mathrm{rad} / \mathrm{s}]$, respectively. Therefore the tractive force coming from engine to equilibrate the reverse forces can be formulated as follows:

$$
\begin{aligned}
& F_{x}=\frac{T_{w}}{r_{w}} \\
& F_{x}=\frac{T_{e} i_{g} i_{f} \eta_{t}}{r_{w}} \\
& F_{x}=\frac{9550 i_{g} i_{f} P_{e} \eta_{t}}{r_{w} N_{e}}
\end{aligned}
$$

where $r_{w}$ is the radius of the wheel $[m]$.

\section{BATTERY MODEL}

Throughout the motion of the vehicle, the electric motor should overcome all resistive forces as given in equation (3). In addition to engine power $P_{e}$, the power demand of electrical auxiliary systems including security systems, comfort systems, lighting systems and information systems $P_{a u x}$ should be also provided by the batteries

$$
P_{\text {Bat }}=P_{e}+P_{a u x}
$$

where $P_{B a t}$ is the electric power demand at the batteries. In electric vehicles, dual polarization model can be used to accurately model the batteries by considering not only the electrical behaviour but also the electrochemical polarization characteristics. As seen from Figure 1(a), dual polarization model consists of battery open circuit voltage $V_{O C}$, battery internal resistance $R_{B a t}$ and RC branches which represent concentration polarization characteristics and electro-chemical polarization characteristics, respectively (Lekshmi and Lal Priya, 2019).

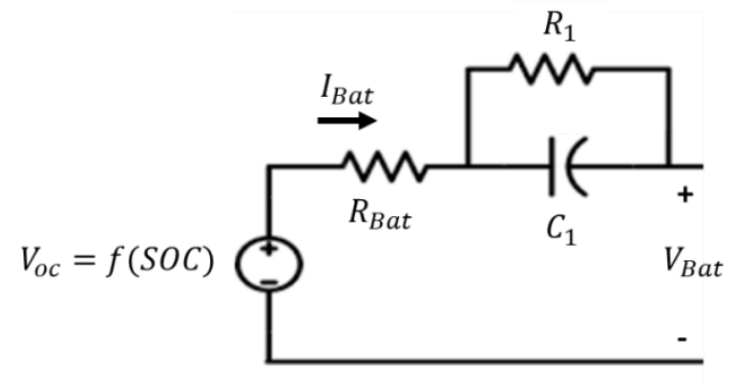

(a)

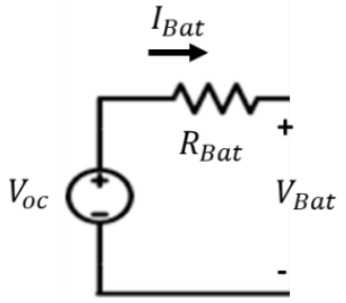

(b)

Figure 1. Battery models; (a) dual polarization model, (b) simplified model 
Since the battery open circuit voltage and the electrical parameters are depend on battery state of charge (SOC) values, calculating the battery current $I_{B a t}$ becomes more complicated. In this manuscript, in order to reduce the complexity, battery electrochemical characteristics are ignored and it is assumed that $V_{O C}$ has a slowly time-varying characteristic and considered constant (Lekshmi and Lal Priya, 2019). Under all these assumptions, according to Figure 1(b) the following equation can be obtained.

$$
V_{o c} I_{B a t}=\left(I_{B a t}\right)^{2} R_{B a t}+P_{B a t}
$$

$P_{B a t}$ is the electric power demand at the batteries. By solving equation (11) for $I_{B a t}$, battery charge / discharge current can be obtained as given below.

$$
I_{B a t}=\frac{V_{O C}}{2 R_{B a t}}-\sqrt{\left(\frac{V_{O C}}{2 R_{B a t}}\right)^{2}-\frac{P_{B a t}}{R_{B a t}}}
$$

The state of charge (SOC) value is an important performance indicator for batteries which denotes the available capacity as a function of the rated capacity. SOC value can be determined by using coulomb counting method as follows

$$
\operatorname{SOC}(t)=\operatorname{SOC}\left(t_{0}\right)-\frac{1}{C_{B a t}} \int_{t_{0}}^{t} \delta(\tau) I_{B a t}(\tau) d \tau
$$

where $C_{B a t}$ is the rated capacity of the battery, $\delta(\tau)$ is the efficiency during charge and discharge operations (Coleman et al., 2007).

\section{SIMULATION MODEL}

The electric vehicle considered in this paper is modeled and simulated in MATLAB / Simulink. The block diagram of the vehicle model is given in figure 2. As it is seen from figure 2, the Simulink model consists of three main sub sections such as resistive force model, traction model and battery model.

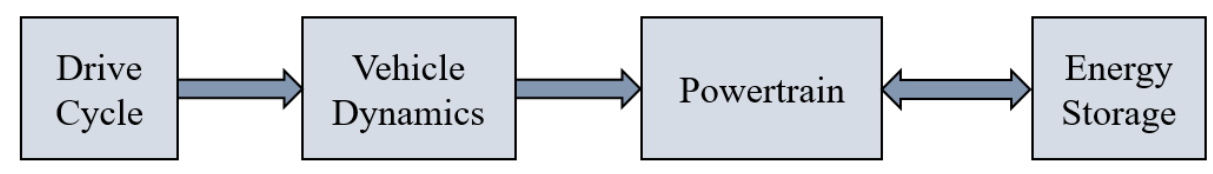

Figure 2. Block diagram of the electrical vehicle

\section{Vehicle Dynamics}

Calculations of the resistive forces which are given in equation (4)-(6) are provided by using vehicle dynamics model given in Figure 3. The vehicle velocity value is taken as external input and it depends on the driving cycle which is selected for simulation process. Besides the parameters such as wind velocity, air density, road incline angle and rolling resistance coefficient are called from the environmental parameters block while drag coefficient, vehicle crossectional area and vehicle mass are read from the vehicle parameters block.

\section{Powertrain Model}

As it is given in Figure 4, this model calculates the required engine power that the vehicle can follow the selected drive cycle by using the equations (7)-(9). Not only the drivetrain parameters such as gearbox reduction ratio, final drive ratio and transmission efficiency, but also the resistive forces calculated by the force model are taken as inputs for this traction model. On the other hand, the relation between torque and speed of the electric motor is obtained via the efficiency-torque-speed curve of the 
selected motor. This efficiency curve is first converted to 2D look up table and then called by the machine parameters block.

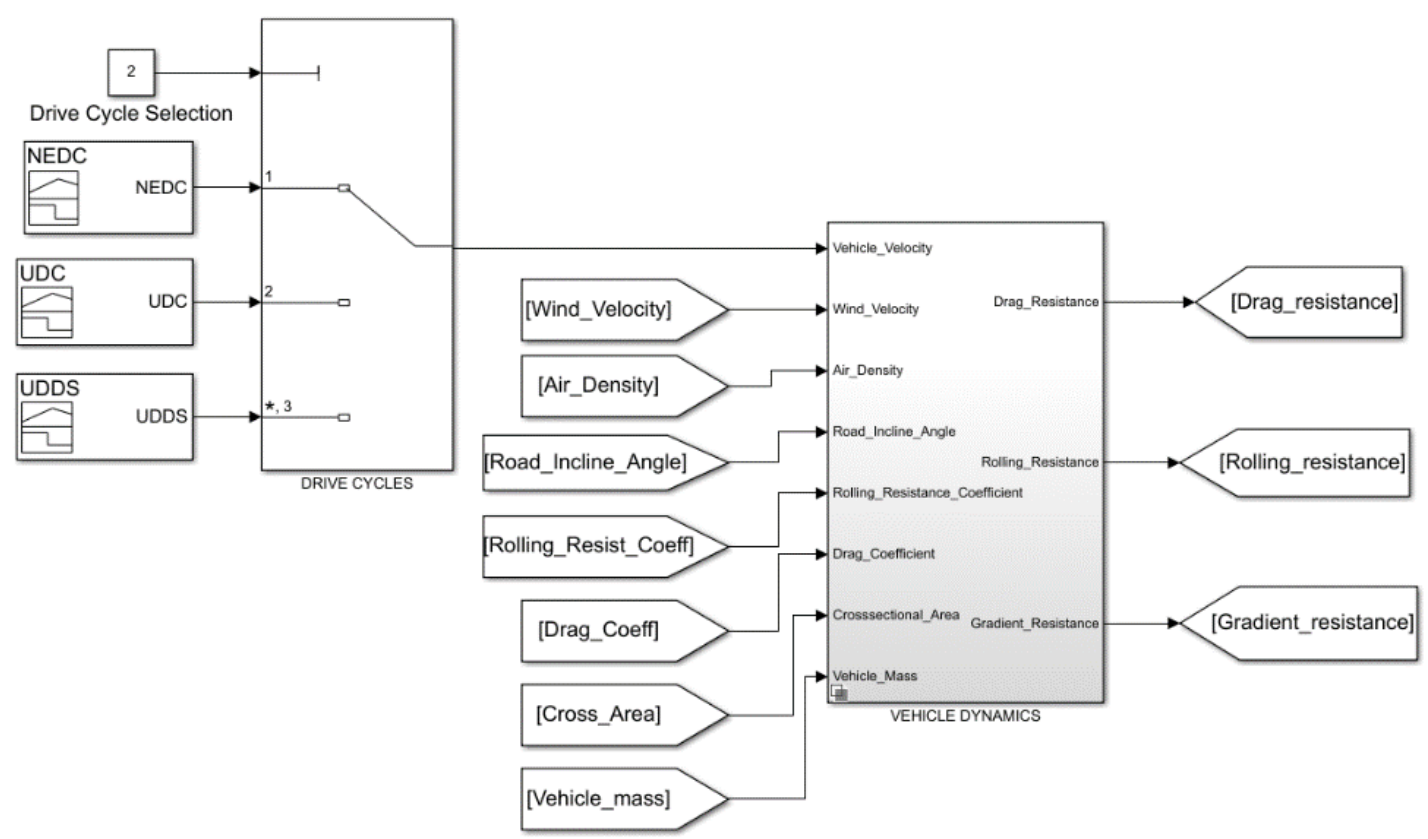

Figure 3. Vehicle dynamics model

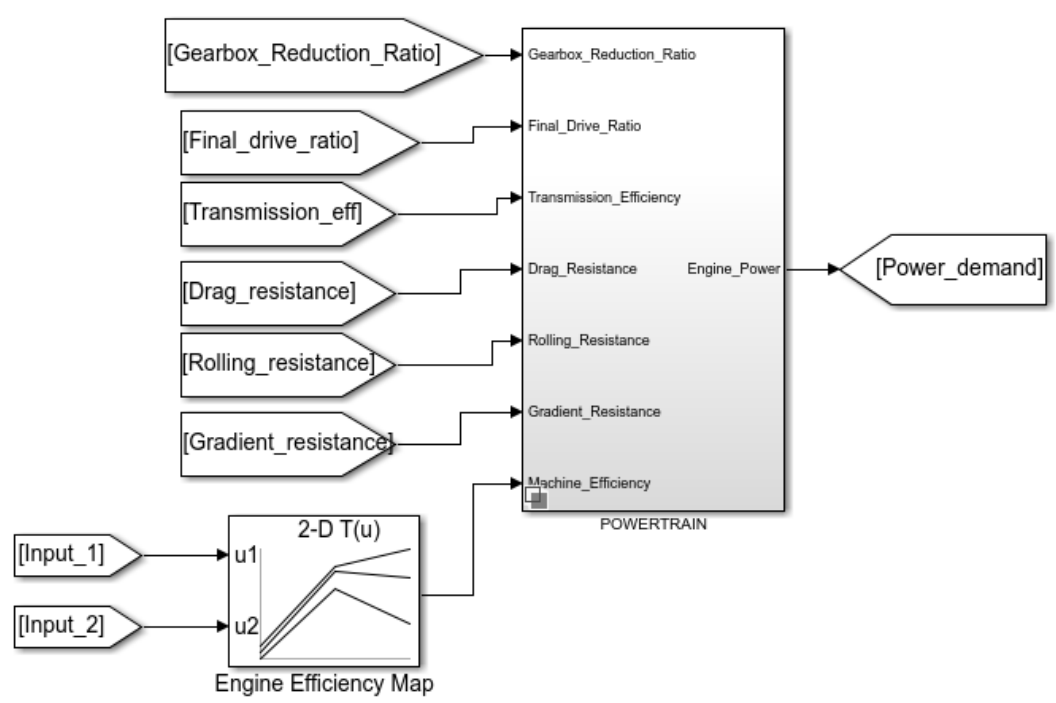

\section{Battery Model}

Figure 4. Powertrain model

In this study, batteries are assumed to be the only energy storage system for the considered vehicle. So the power required to propel the vehicle is supplied by the batteries. On the other hand batteries are charged by the kinetic energy recovered during regenerative braking. In this model the amount of energy consumed or generated during the driving cycle, the value of battery charge and discharge current and battery state of charge are calculated as given in equations (10)-(13). It is considered that the electric motor is braked with $100 \%$ gain in regenerative mode. Simulink model for the energy storage system is given in Figure 5. 


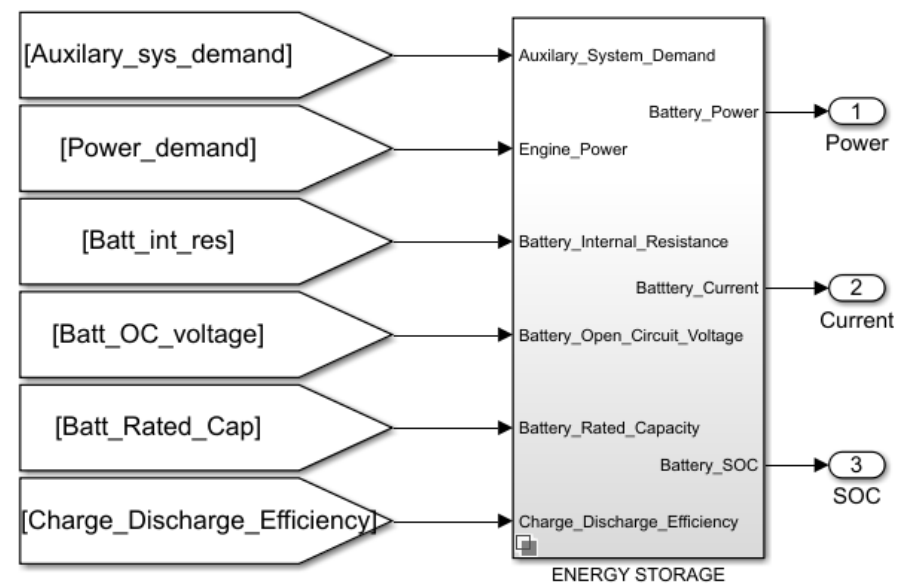

Figure 5. Battery model

\section{SIMULATION RESULTS}

The simulation for electric drive vehicle can be implemented for different drive cycles and considering various conditions. In this section simulation results of NEDC, UDDS and NREL drive cycles are evaluated.

\section{NEDC and UDDS Drive Cycles}

It is expected that NEDC drive cycle (United Nations Regulations, 2013) represents the ordinary usage of a vehicle in Europe. It includes four repeated urban drive cycles at the beginning and one extraurban drive cyle at the end of drive cycle. The test takes 1180 seconds with an average speed of $33 \mathrm{~km} / \mathrm{h}$. The NEDC drive cycle is given in Figure 6-a. UDDS refers to Urban Dynamometer Drive Cycle which a mandatory dynamometer test applied by United States Environmental Protection Agency. The UDDS (EPA, 1978) is regarding to fuel economy in city conditions. The cycle takes a $12 \mathrm{~km}$ long urban route with $32 \mathrm{~km} / \mathrm{h}$ average speed and $92 \mathrm{~km} / \mathrm{h}$ maximum speed. The UDDS is given in Figure 6-b.

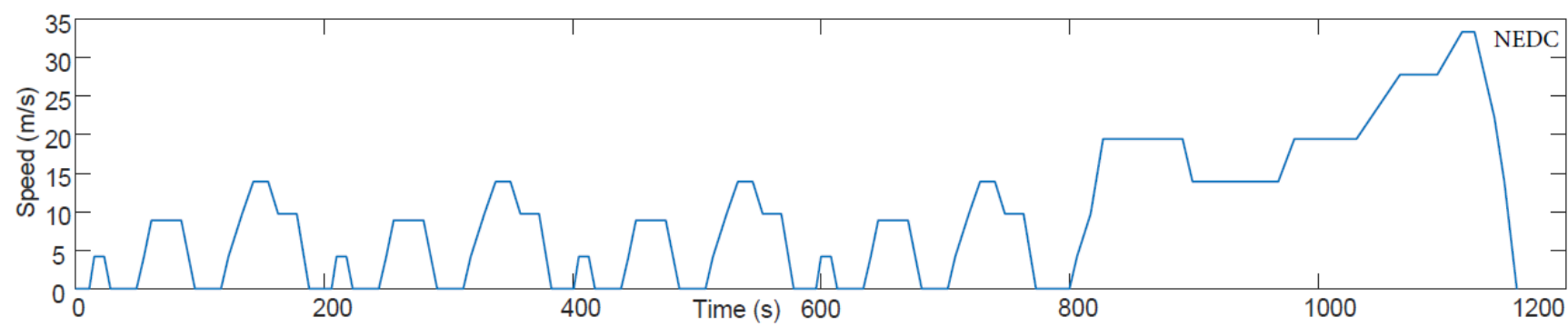

(a)

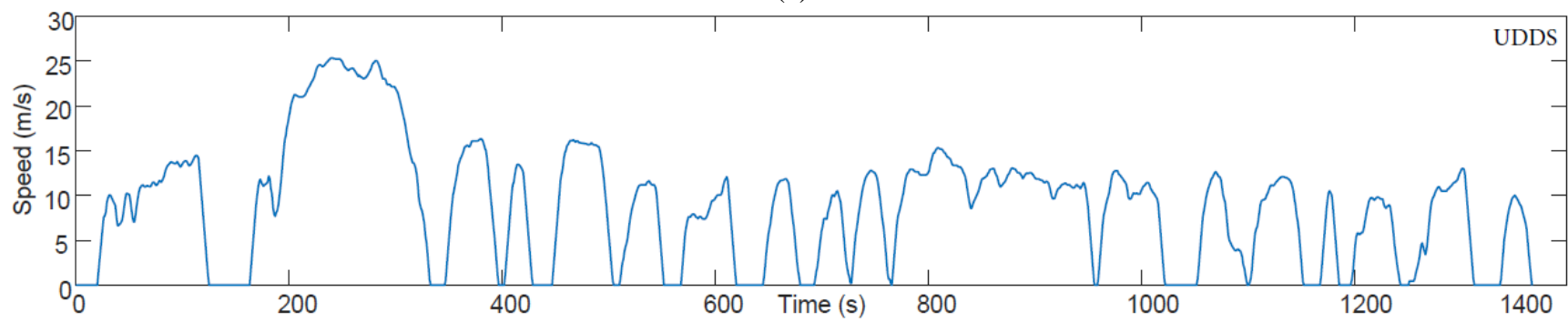

(b)

Figure 6. Speed vs. time graphs of (a) NEDC and (b) UDDS

In the motoring mode, the battery power of vehicle is positive and this means that the engine provides torque in the direction of vehicle and it accelerates. In regenerative mode, the battery power of vehicle is negative and the motor works as a generator. In this mode the vehicle decelerates sluggishly. 
In Figure 7-a, the battery power of vehicle measured during the NEDC drive cycle is given. During the four urban drive cycles, the battery power demand looks similar each other. It is positive when the vehicle needs to be accelerated and it is negative while the vehicle is decelerating. The major difference for battery power both positive and negative manner occur in the last part of the drive cycle since the power demand that is required to speed up the vehicle to $120 \mathrm{~km} / \mathrm{h}$ is large, and likewise to stop the vehicle while it is moving with $120 \mathrm{~km} / \mathrm{h}$ speed. The maximum power demand for NEDC drive cycle is measured as approximately $32 \mathrm{~kW}$ and the maximum regenerative power is measured as $18.8 \mathrm{~kW}$. Battery power vs. time graph of UDDS drive cycle is given in Figure 7-b. The power demand for this drive cycle become maximum between 180 and 320 seconds. On the contrary, while the vehicle is cruising, the power demand reaches the minimum value (850s-900s). The maximum power demand for UDDS drive cycle is measured as approximately $35 \mathrm{~kW}$ and the maximum regenerative power is measured as $17 \mathrm{~kW}$.
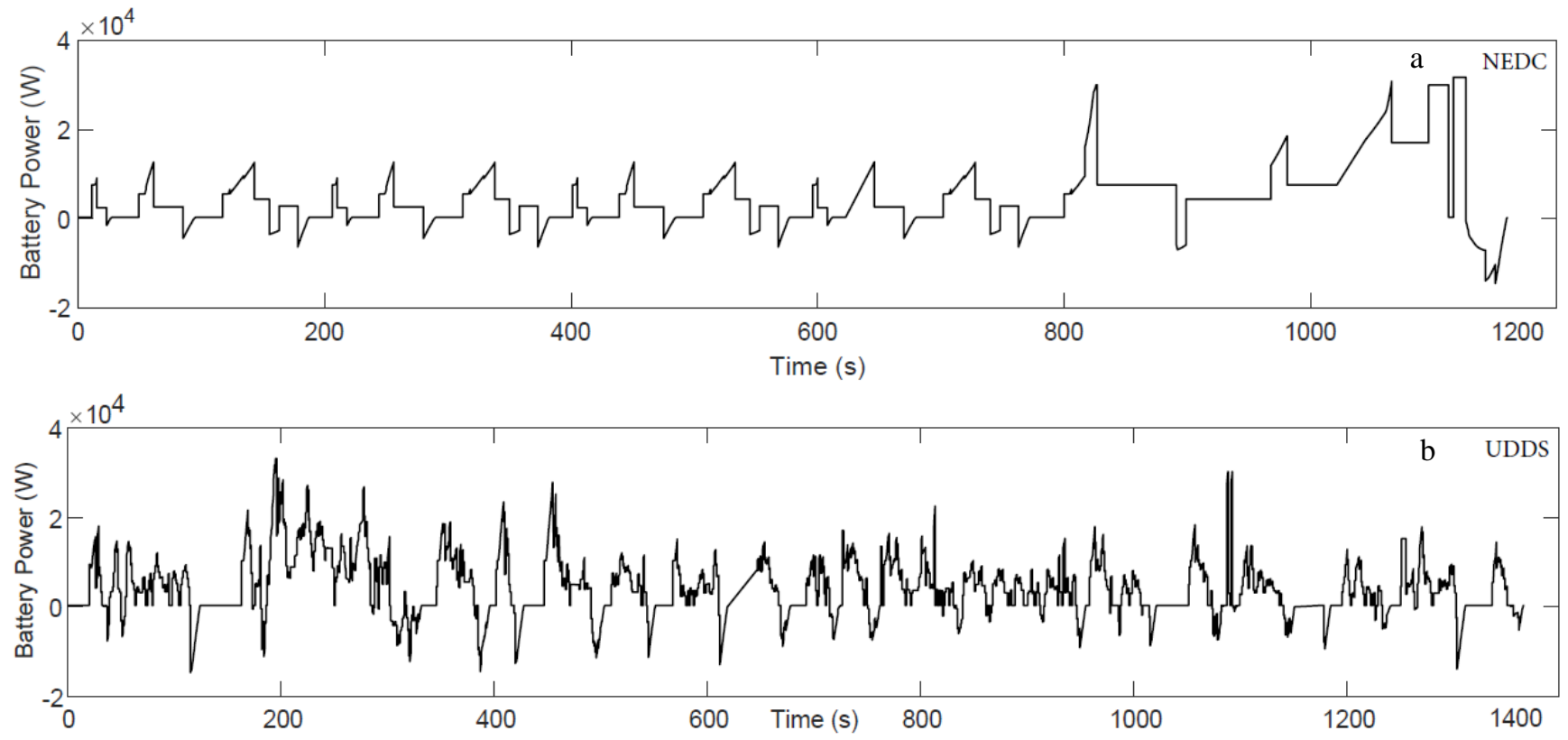

Figure 7. (a) Battery powers vs. time for (a) NEDC and (b) UDDS

It is assumed that the battery is full $(100 \%)$ for both drive cycles at the beginning of the simulation. At the end of the simulation, the state of charge (SOC) of the battery is measured as $93 \%$ for NEDC drive cycle and $92.2 \%$ for UDDS drive cycle. Also the state of the battery for both drive cycles can be found in details in Figure 8. It can be seen readily either battery is charged or discharged at which time stamp.

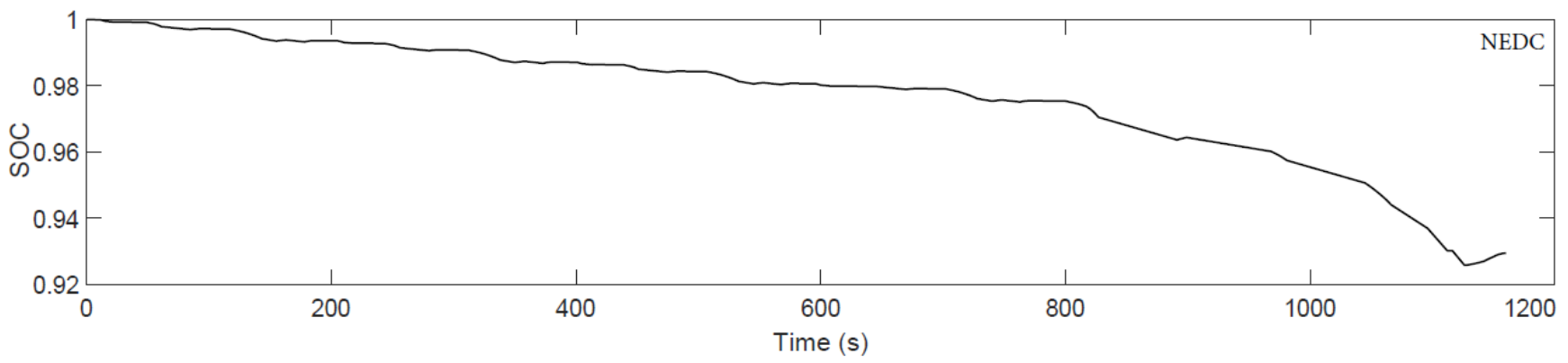

(a)

Figure 8. SOC values vs. time for (a) NEDC and (b) UDDS 


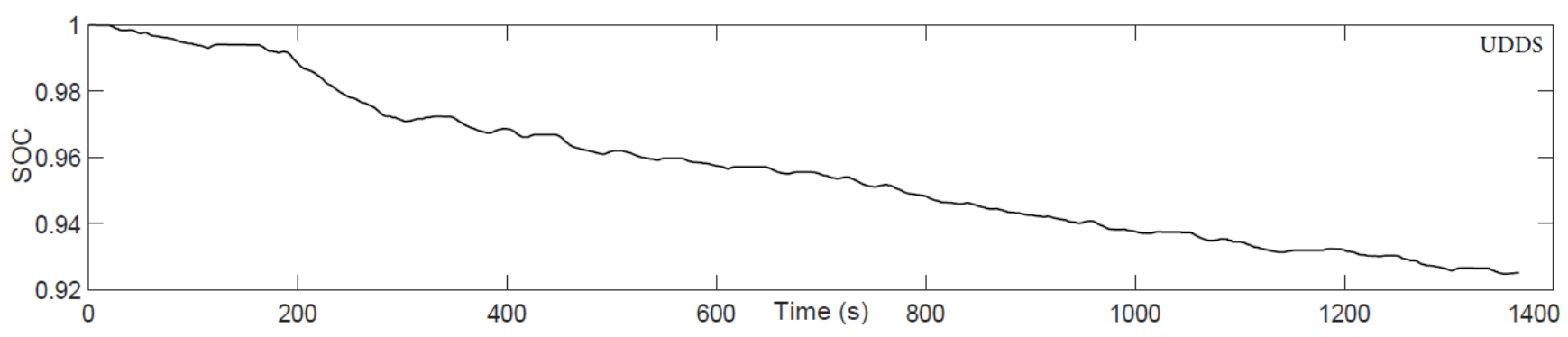

(b)

Figure 8. SOC values vs. time for (a) NEDC and (b) UDDS (continued)

\section{NREL Drive Cycle}

This drive cycle was developed by National Renewable Energy Laboratory in order to test class 3 electric vehicle's performance (NREL DriveCAT, 2019). Rapid accelerations and long time stops draw attention in NREL drive cycle. The distance of path is about $11 \mathrm{~km}$ long, and the average speed is 11 $\mathrm{km} / \mathrm{h}$. The NREL class 3 drive cycle is given in Figure 9.

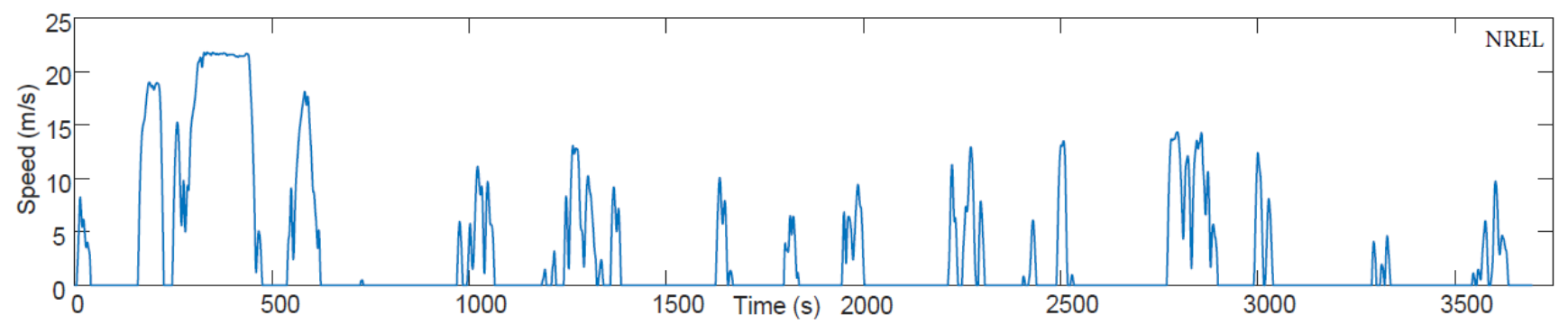

Figure 9. Speed vs. time graphs of NREL class 3 drive cycle

Power demand in NREL drive cycle is substantially similar to the previous drive cycles (see Figure 10-a). But the SOC value of battery differs from the others. This drive cycle requires more power at the beginning of trip and this cause to drastic drop in SOC level of battery. Again it is assumed that the battery is full (100\%) at the beginning of the simulation. At the end of the simulation, the state of charge (SOC) of the battery is measured as $91 \%$ for NREL drive cycle. Also the state of the battery can be found in details in Figure 10-b.
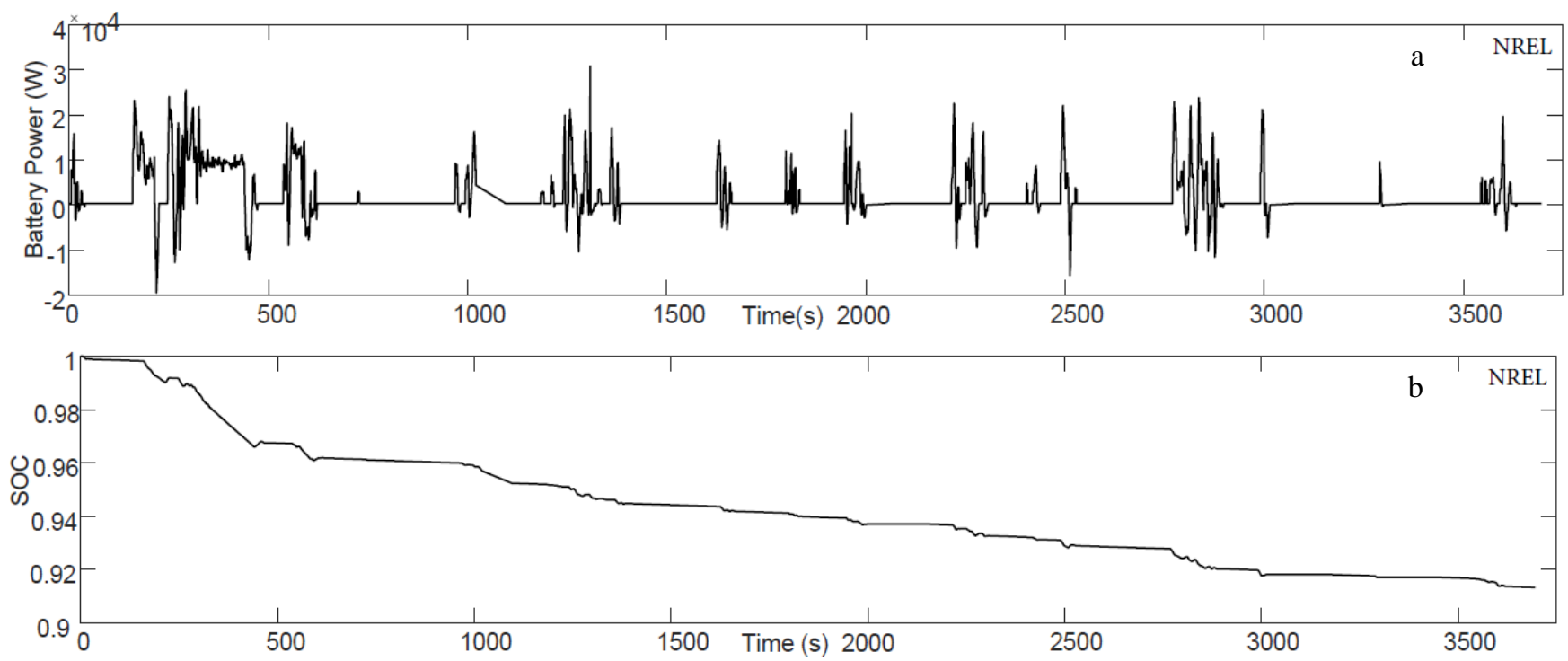

Figure 10. (a) Battery power values vs. time (b) SOC values vs. time graphs of NREL class 3. 


\section{DISCUSSION}

The EDV model is implemented based on the block diagram given in Figure 2. The motion of EDV is modeled based on Newton's second law considering gradient, rolling and aerodynamic resistances and traction force. Three drive cycles were taken into account to calculate power demand which is required to change speed to desired level. Although these three drive cycles differ each other in consideration of their characteristics, EDV model provides the required power (see Figures 7 and 8a).

One of the most important parts of EDV is storage system. Since for electric vehicles which is only powered by batteries, SOC and SOH (state of health) of battery and range of vehicle issue is still a bottleneck. New generation batteries help to EDVs to enlarge their travel range more than old-fashioned batteries. But SOC and SOH of battery depend on the power and current values of battery which is regarding to the driving characterictics. With the help of EDV's recuperation capability, it is possible to improve SOC of battery. But braking frequency and speed of vehicle specify the efficiency of regeneration. For instance, when we consider UDDS drive cycle there are frequent stops comparing the other drive cycles. Consequently, the energy recuperation is much more than the others. But power demand is also higher than the other drive cycles. Because of that SOC values of NEDC and UDDS drive cycles are about to same.

Table 1. Maximum and minimum battery currents of different scenarios.

\begin{tabular}{lccc}
\hline & NEDC & UDDS & NREL \\
\cline { 2 - 4 } Maximum Battery Current & $100 \mathrm{~A}$ & $118 \mathrm{~A}$ & $95 \mathrm{~A}$ \\
Minimum Battery Current & $-50 \mathrm{~A}$ & $-49 \mathrm{~A}$ & $-60 \mathrm{~A}$ \\
\hline
\end{tabular}

One of the parameters that affect SOH is battery current. Instantaneous huge power demand and large current values are determinant of $\mathrm{SOH}$ value. Battery currents for different scenarios are given in Table 1. Positive battery current corresponds to motoring mode and battery is discharging, while negative battery current refers to regenerative mode and battery is in charge. The battery currents in Table 1 are reasonable but it is possible to improve battery health by using hybrid energy storage system instead of single battery system.
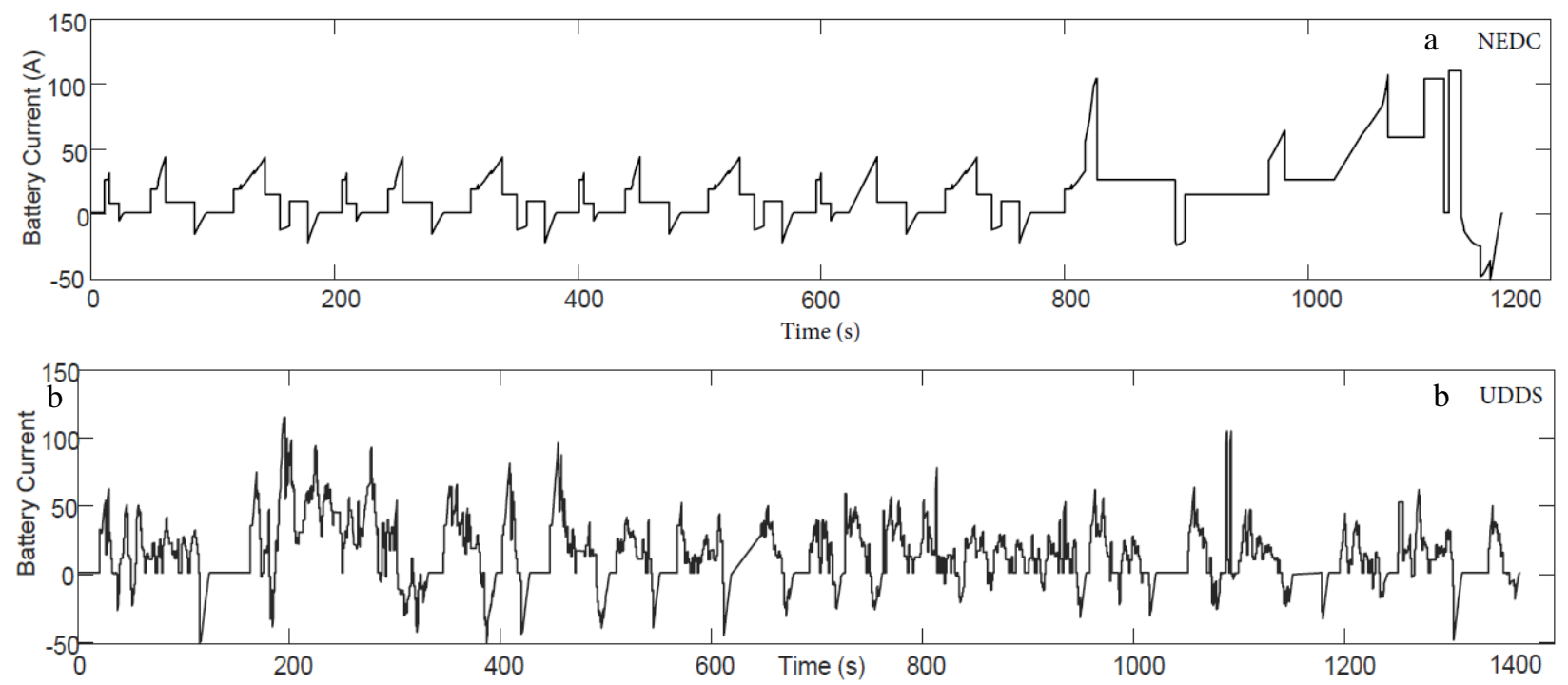

Figure 11. Battery Currents (a) NEDC (b) UDDS (c) NREL 


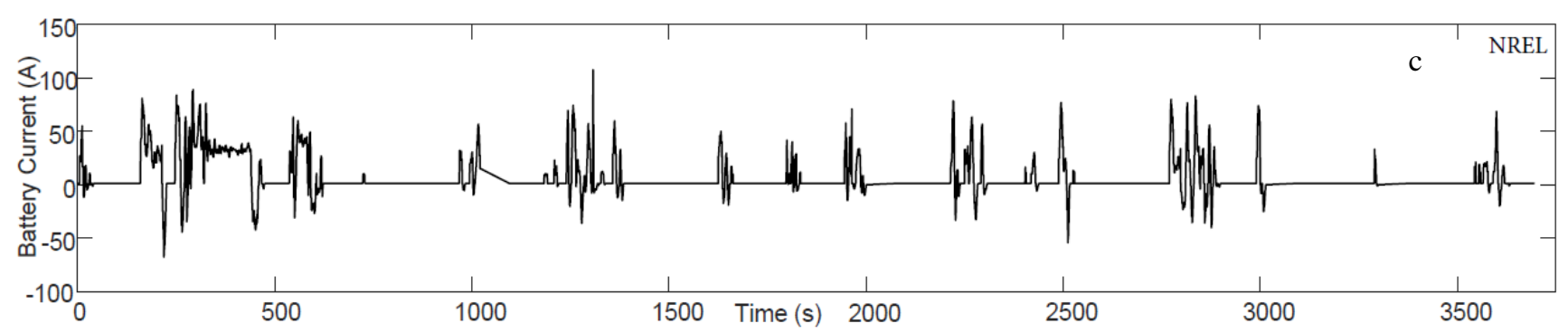

Figure 11. Battery Currents (a) NEDC (b) UDDS (c) NREL (continued)

\section{CONCLUSION}

In this manuscript, an analytical model and simulation of EDV is proposed using MATLAB/Simulink environment. The proposed model has four main blocks such as drive cycle, vehicle dynamics, powertrain model and battery model. Simulations are performed with three different drive cycles such as: UDDS (Urban Dynamometer Driving Schedule), NEDC (The New European Driving Cycle) and NREL (National Renewable Energy Laboratory Class-3). Results show that obtained battery power demand values correspond with the speed profile of the selected drive cycle. Power demand is positive when the vehicle needs to be accelerated and it is negative while the vehicle is decelerating. This mentioned negative power demand values also demonstrates that proposed model can handle the regenerative braking for EDV where the motor works as a generator and charges the battery. Charging the battery under braking results in an increment on the battery SOC values and provides more efficient battery usage. It must be noted that the amount energy regenerated depends on the drive cycle in terms of braking frequency and speed of vehicle.

\section{ACKNOWLEDGEMENT}

This study was supported by the Scientific Research Projects Fund of Eskisehir Osmangazi University by the project number: 202015008.

\section{REFERENCES}

Amjad, S., Neelakrishnan, S. and Rudramoorthy, R. (2010). Review of design considerations and technological challenges for successful development and deployment of plug-in hybrid electric vehicles. Renewable and Sustainable Energy Reviews, 14(3), pp.1104-1110.

Burke, A. (2007). Batteries and Ultracapacitors for Electric, Hybrid, and Fuel Cell Vehicles. Proceedings of the IEEE, 95(4), pp.806-820.

Castro, T., de Souza, T. and Silveira, J. (2017). Feasibility of Electric Vehicle: Electricity by Grid $\times$ Photovoltaic Energy. Renewable and Sustainable Energy Reviews, 69, pp.1077-1084.

Coleman, M., Chi Kwan Lee, Chunbo Zhu and Hurley, W., (2007). State-of-Charge Determination From EMF Voltage Estimation: Using Impedance, Terminal Voltage, and Current for Lead-Acid and Lithium-Ion Batteries. IEEE Transactions on Industrial Electronics, 54(5), pp.2550-2557.

Ehsani, M. (2013). Electric, hybrid, and fuel cell vehicles, introduction. In Transportation technologies for sustainability (pp. 492-493). Springer New York,

EPA (1978). United States Environmental Protection Agency Federal Test Procedure, LA-4 cycle (CFR 40, 86, App.I)

Hegazy, S., Rahnejat, H., \& Hussain, K. (1999). Multi-body dynamics in fullvehicle handling analysis. Proceedings of the Institution of Mechanical Engineers, Part K: Journal of Multi-body Dynamics, 213(1), 19-31. 
Heywood JB. (1988). Internal Combustion Engine Fundamentals. McGraw-Hill Education.

Hota, A., Juvvanapudi, M. and Bajpai, P. (2014). Issues and solution approaches in PHEV integration to smart grid. Renewable and Sustainable Energy Reviews, 30, pp.217-229.

Larminie, J. and Lowry, J. (2012). Electric vehicle technology explained, second edition. 2nd ed. Wiley.

Lekshmi, S. and Lal Priya, P.S. (2019). Mathematical modeling of Electric vehicles - A survey. Control Engineering Practice, 92, p.104138.

Matsuo, I., Miyamoto, T., and Maeda, H., (2000). The Nissan Hybrid Vehicle. SAE Technical Paper 2000-01-1568.

NREL DriveCAT - Chassis Dynamometer Drive Cycles. (2019). National Renewable Energy Laboratory.

Peng, M., Liu, L. and Jiang, C. (2012). A review on the economic dispatch and risk management of the large-scale plug-in electric vehicles (PHEVs)-penetrated power systems. Renewable and Sustainable Energy Reviews, 16(3), pp.1508-1515.

Schaltz, E. (2011). Electrical Vehicle Design and Modeling. Electric Vehicles - Modelling and Simulations. InTech Open.

Shareef, H., Islam, M. and Mohamed, A. (2016). A review of the stage-of-the-art charging technologies, placement methodologies, and impacts of electric vehicles. Renewable and Sustainable Energy Reviews, 64, pp.403-420.

Suh, I.-S., Hwang, K., Lee, M., \& Kim, J. (2013). In-wheel motor application in a 4wd electric vehicle with foldable body concept. In 2013 International electric machines \& drives conference. IEEE, Chicago, IL, pp. 1235-1240,

Tie, S. and Tan, C. (2013). A review of energy sources and energy management system in electric vehicles. Renewable and Sustainable Energy Reviews, 20, pp.82-102.

United Nations Regulations (2013). E/ECE/324/Rev.2/Add.100/Rev.3-E/ECE/TRANS/505/Rev.2/ Add.100/Rev.3 